below the poverty line, that is, those being maintained by the tax-payers, will steadily increase. In 1930 , round about 10 per cent of the families had more than 40 per cent of the pregnancies, 45 per cent of the still-births, 53 per cent of the infant plus child mortalities and 63 per cent of the miscarriages. In 1950 , the 10 per cent will have become at least 30 per cent. Nothing short of massacre can alter that now. Births cannot be retrospective. If nothing is done and the process goes on, in 1970, the submerged tenth will be multiplied by seven. This means that, apart altogether from the increasing load of old people, some 30 per cent of the population will have to face the problem of supporting the rest of the community."

\section{The Short-Mayo Composite Aircraft}

Expermental flights of the two units of this combination are proceeding successfully at Rochester. Mercury, a four-engined monoplane seaplane, which is to be attached to the top of, and launched from, Maia, a four-engined monoplane flying boat of a modified Empire type, have both flown separately, and have now to carry out trials, taking off, flying and landing as a combined unit. These will be followed by tests involving releasing in the air and landing as separate units, their normal functions. This experiment is one of fundamental importance in the problem of high-speed long-range flight, as it represents one of several possible methods of getting an aircraft into the air with a load which would make taking-off unsafe or even impossible for a machine under its own power. Heavy loads are not only economical from the transport point of view, but also high wing loading is essential for economical power consumption in high-speed flight. Reduction in engine power used not only reduces costs, but also increases the machine's range on a given fuel tank capacity. When this problem is successfully overcome, it will also help in the case of land aircraft, allowing the use of smaller aerodromes for large heavily loaded commercial machines.

ANother point of the composite type of aircraft is that it will allow the engines of the launched machine to be of the supercharged type necessary for high altitude flying, without their having to carry the complications necessary to allow them to function efficiently at ground level, for the purpose of taking off, as well. Other methods of attaining the same object at present being developed are (1) the use of various wing attachments such as slots or flaps, wing surface and contour changing devices, variable pitch propellers, to increase the speed range of the aircraft, and (2) catapulting the machine into the air, giving it the speed necessary for flight with its high loading, from a momentum applied to it from an external source of power, usually either explosive or hydraulic.

\section{Progress of Marine Engineering}

ON September 14, Mr. S. J. Pigott, director-incharge of the Clydebank Works of John Brown and
Co., Ltd., where the Queen Mary was built, delivered the presidential address to the Institute of Marine Engineers. In the main it was a review of the development in marine engineering during the last sixty years. The era 1877-87, he said, might be designated "The Advent of Steel in Engineering". In that decade it was possible to raise the pressure in cylindrical boilers to $160 \mathrm{lb}$. per sq. in., and at the same time forced draught was introduced. The next decade, 1887-97, saw the development of the quadruple-expansion engine, which in the period 1897-1907 attained its maximum size. The year 1897 was also marked by the use by Sir Charles Parsons of the marine steam turbine, and in 1904 the Cunard Steamship Company equipped the Carmania with a high-pressure turbine driving a centre-line shaft and exhausting to a low-pressure turbine on each wing-shaft. The Diesel engine first made its appearance on shipboard in 1903 in the small Russian tanker Vandal. Another landmark was the fitting of geared turbines in the Vespasian in 1909. In 1910 impulse turbines as opposed to the earlier reaction turbines were fitted in H.M.S. Bristol, and to-day, the most highly powered British naval vessel, H.M.S. Hood, is propelled by impulse turbines with gearing. If the era 1927-37 has seen no epochmaking development, it has produced progressive designs as is seen in the cross-channel motor-ship Prince Baudouin, the turbo-electric P. and O. liner Viceroy of India, and last but not least the Queen Mary and Normandie.

\section{Miniature Ball Bearings}

As invention which, apart from its intrinsic merits as a mechanical development, promises to be of especial interest in a scientific sense, is the introduction by a Swiss manufacturer of a range of miniature ball bearings. Ordinary bearings of this class have been made in sizes varying from half an inch to five feet in diameter overall; but nothing small enough has been available to satisfy the requirements of small and sensitive instruments. The bearings now obtainable as a result of this invention are of several different types and vary in size from 1 to 22 millimetres in diameter overall. They are thus of suitable size for use in such devices as small motors, recorders, meters, clockwork, tachometers and scientific instruments of many kinds in which measured movements are produced by infinitesimal forces, and friction must be eliminated as far as possible. Comparative tests on these bearings and the jewelled bearings they are intended to replace show advantages under three different modes of operation. The time to damp down a rotary motion was in some cases so high as eight times that when plain pivots were used and twenty times that when tapered pivots were used, though there is a good deal of variation in the results. In an oscillatory test the corresponding figures were about 4 and 15 , while in the deviation test the results claimed are also favourable. As these new bearings are obtainable at moderate prices, it is probable that, after adequate trials, they will play an important part in the 